\title{
Curettage and Cementation in Giant Cell Tumour of the Distal Tibia Using Polypropylene Mesh for Containment: A Case Report
}

\author{
KL Pan*, FRCS (Glasg), WH Chan, MS (Orth) (UKM) \\ *Department of Orthopaedics, Faculty of Medicine and Health Sciences, Universiti Malaysia Sarawak, \\ Sarawak General Hospital
}

\begin{abstract}
Giant cell tumours of bone are best treated by extended curettage and filling in of the defect with cement or bone graft. In more advanced stages, when there is extensive loss of cortical bone cover, containment of the filling material is not possible and resection and reconstruction is required. We report a case of a recurrent giant cell tumour of the distal tibia in a 21-year-old female with extensive cortical bone loss in which polypropylene surgical mesh was used to contain the bone cement, thus avoiding a resection.
\end{abstract}

\section{INTRODUCTION}

Giant cell tumours rarely occur around the ankle ${ }^{1}$. When these growths occurs in the distal tibia, in early stages, it is amenable to extended curettage and filling of the resulting defect with cement or bone graft. This requires sufficient cortical bone to contain the cement. When more than one "wall" of the affected site has been eroded, containment of the cement is no longer a viable option; instead, treatment requires resection and reconstruction. At the distal tibia, this often requires fusion of the ankle, a procedure that physicians would obviously like to avoid in young patients. We report here a case of a recurrent giant cell tumour at the distal tibia with loss of the anterior and posterior cortex in which extended curettage and cementation was performed with the aid of a synthetic polypropylene mesh to contain the cement.

\section{CASE REPORT}

A 21-year-old female first experienced pain and swelling over her right ankle in December 2007. After initial traditional massage, she was seen by an orthopaedic surgeon at a private hospital and was diagnosed with a giant cell tumour of the distal tibia. Curettage and autogenous (iliac crest) bone grafting was performed in February 2008. The swelling and pain subsequently recurred and she was referred to our centre six months postoperatively.

A plain X-ray (Fig 1) and MRI taken at that time showed obvious recurrence with soft tissue extension and loss of the anterior and posterior cortex at the tumour site. The medial and lateral walls were intact. We performed extended curettage and bone cementation in October 2008 as described below.

The incision was made using the previous operative scar over the anterolateral aspect of the ankle. The soft tissue extent of the anterior region of the tumour was demarcated and then removed. This window was extended proximally and then using a high-speed burr, a thin rim of normal bone was removed from the medial and lateral cortices. Posteriorly, an area of 4 X $3 \mathrm{~cm}$ was devoid of bone after removal of the tumour. The firm, leathery posterior periosteum was palpated and left intact. To fill the defect, a double layer of polypropylene surgical mesh, slightly bigger than the measured defect was cut and placed in the defect (Fig 2). Bone cement, while still fluid, was poured into the defect, allowed to flow proximally into the medullary cavity, and abut the remaining subchondral bone and cartilage distally to provide immediate post-operative support. After setting the cement, the wound was closed.

Postoperatively, the patient was allowed partial weightbearing, progressing to full weight-bearing over a period of six weeks. When last seen at follow-up 13 months later, she was ambulating with a normal gait with occasional aches after walking long distances. Plain radiographs did not show any evidence of recurrence.

\section{DISCUSSION}

Giant cell tumour rarely occurs at the ankle bones, the distal tibia, fibula or talus. When discovered early, extended curettage with a large window, high speed burring, and filling of the cavity with bone cement or bone graft is the universally accepted mode of treatment ${ }^{2}$. This may be supplemented with instillation of phenol or liquid nitrogen to kill any remaining tumour cells. Bone cement has the advantage of generating heat to kill off any remaining tumour cells, yet offers immediate structural support, and the greater ease of detecting recurrence radiologically. Bone graft is biological and is not harmful to the articular cartilage. Both methods require the filling material to be "contained". 


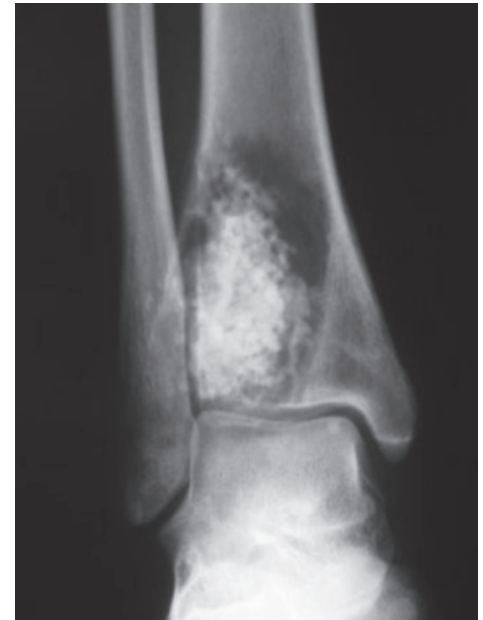

Fig. 1A: Plain x-ray AP view showing obvious recurrence after first surgery.

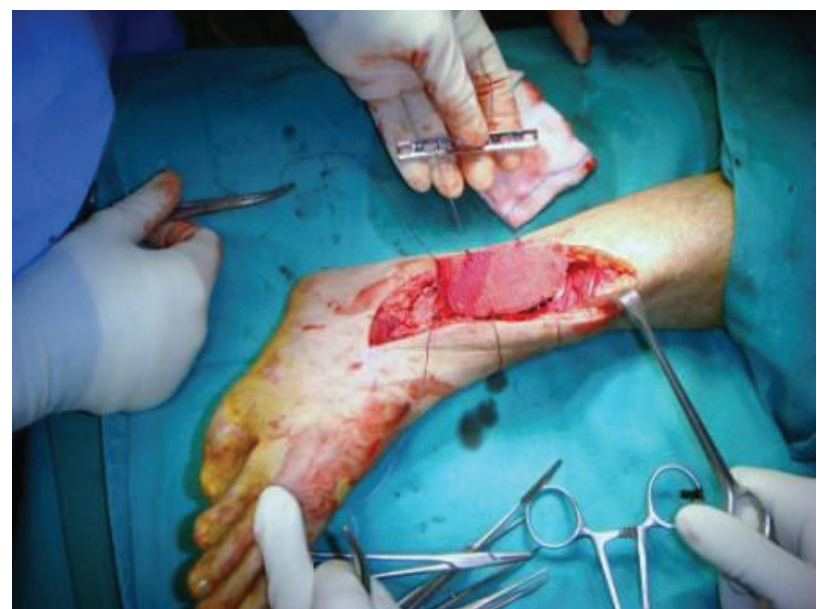

Fig. 2A: Polypropylene mesh before insertion into defect.

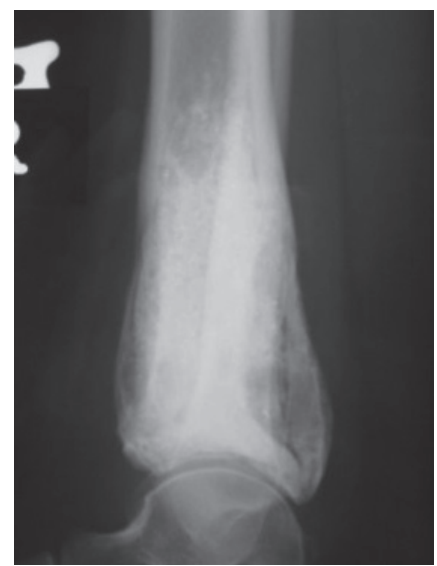

Fig. 3: Plain $x$-ray $F / U$ at 13 months showing reconstituted posterior cortex.

When extensive or multiple defects in the cortical walls cannot provide this containment, a resection is performed. The resulting defect is reconstructed with a tumour megaprosthesis or a fusion is often performed across the joint using autografts or allografts ${ }^{3-5}$.

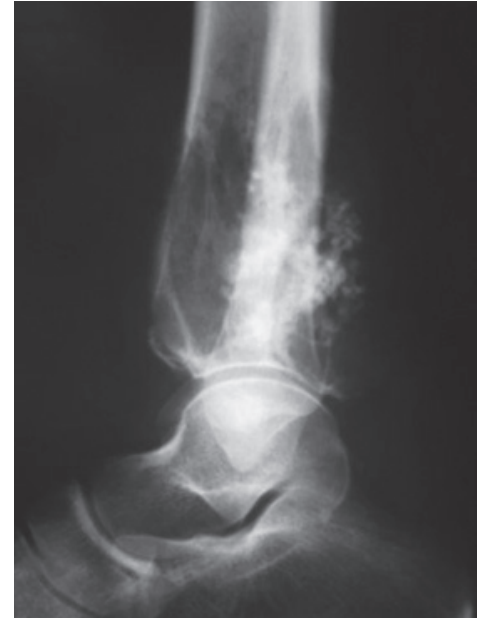

Fig. 1B: Plain x-ray lat. view showing loss of anterior and posterior cortices.

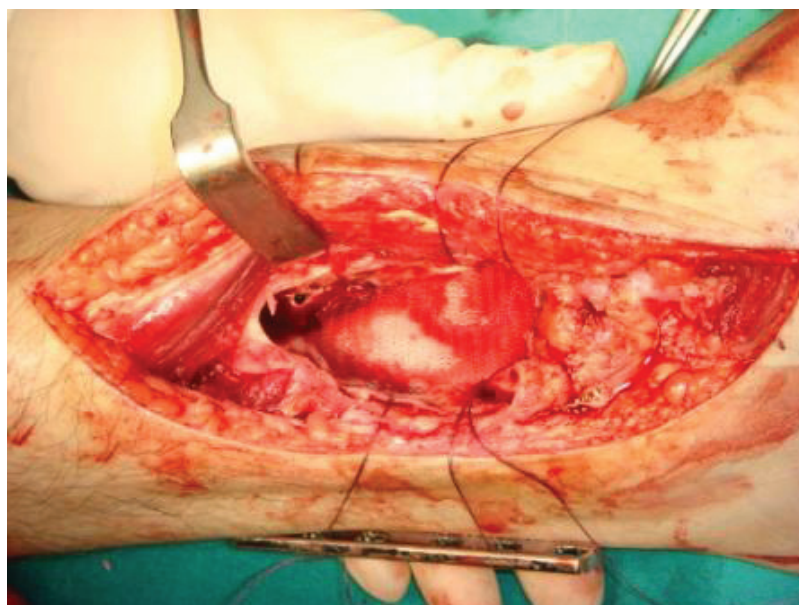

Fig. 2B: Mesh in place, held by strings.

In a young patient with a lesion at the ankle, the use of a tumour prosthesis or fusion are not satisfactory alternatives. For this patient, we avoided resection and reconstruction with the aid of a polypropylene mesh to contain the cement after completion of extended curettage. By using a double layer of the mesh, we ensured that there was no leakage of cement (as seen in postoperative x-rays). There was initial concern about the transmission of heat across the mesh causing damage to the soft tissue and neurovascular bundle. However, later follow-up x-rays showed reconstitution of the posterior cortex (Fig 3), indicating an intact and live periosteum that abutted the mesh and cement at the time of surgery. As far as we know, this modification has not been reported before. Close follow-up is required and any further recurrence can still be treated by curettage or resection.

The use of a mesh to cover large defects extends possible indications for curettage as treatment for giant cell tumours and if successful in the long term, is a much better treatment alternative than the use of a tumour prosthesis or fusion across a joint. 


\section{REFERENCES}

1. Kamath S, Jane M, Reid R. Giant cell tumour around the foot and ankle. J Foot Ankle Surg 2006; 12(2): 99-102.

2. Szendra M. Giant cell tumour of bone. Review Article. J Bone Joint Surg 2004; 86-B(1): 5-12.

3. Abudu A, Grimer RJ, Tillman RM, Carter SR. Endoprosthetic replacement of the distal tibia and ankle joint for aggressive bone tumours. Int Orthop. 1999; 23(5): 291-4.

4. Campanacci DA, Scoccianti G, Beltrami G, Mugnaini M, Capanna R. Ankle arthrodesis with bone graft after distal tibia resection for bone tumors. Foot Ankle Int. 2008 Oct; 29(10): 1031-

5. Saglik Y, Yildiz Y, Atalar H, Gunay C. The use of fibular autograft and ankle arthrodesis for aggressive giant cell tumor in the distal tibia: a case report. Foot Ankle Int. 2008 Apr; 29(4): 438-41. 